* Doutoranda em Direito Ambiental Internacional (bolsista CAPES), pela Universidade Católica de Santos. Mestre em Direito Ambiental (bolsista CAPES), pela Universidade Católica de Santos. Pósgraduada em Direito Processual Civil e Direito Processual do Trabalho, pela Universidade Católica de Santos. Conciliadora capacitada pela Escola Paulista da Magistratura. Advogada e Jornalista. Email: gabrielasoldanogarcez (a)adv.oabsp.org.br

** Doutor e mestre em Direito pela Pontifícia Universidade Católica de São Paulo. Professor Titular da Universidade Santa Cecília. Professor convidado da Escola Superior do Ministério Público. Professor titular da pósgraduação (mestrado e doutorado) e graduação da Universidade Católica de Santos. E-mail: gpassosfreitas@uol.com.br

\section{Governança, globalização e atores não estatais: uma análise sob a perspectiva do Direito Internacional}

\author{
GOVERNANCE, GLOBALIZATION AND NON-STATE
} ACTORS: AN ANALYSIS FROM THE PERSPECTIVE OF INTERNATIONAL LAW

* Gabriela Soldano Garcez ** Gilberto Passos de Freitas

Resumo: $\mathrm{O}$ artigo objetiva tratar da conexão entre governança e atores não estatais, fenômeno intensificado no atual cenário mundial de globalização. Inegavelmente, tais atores fazem parte dos mecanismos de implementação e eficiência da governança, entretanto ainda figuram no centro do debate doutrinário acerca (da ausência ou reconhecimento) de suas personalidades jurídicas. Neste panorama, o presente artigo aborda, primeiramente, a governança e a globalização, indicando as três correntes a respeito desta última. Após, destaca quais são os principais atores não estatais na atualidade, avaliando a atividade dos mesmos para os processos de governança. Por fim, analisa a controvérsia do reconhecimento da personalidade jurídica internacional destes atores não estatais.

Palavras-chave: Governança. Globalização. Atores não estatais. Personalidade jurídica. Direito internacional.

Abstract: The article aims to address the connection between governance and non-state actors, phenomenon intensified in the current world scenario of globalization. Undeniably, these actors are part of the implementation mechanisms and efficiency of governance, however they still appear in the center of the doctrinal debate about (the lack or recognition) of their legal personalities. According to this background, this article discusses, at first, governance and globalization, studying the three lines of thought about globalization. After, highlights the main nonstate actors nowadays, examing the activity of those for the governance processes. Finally, it analyzes the controversy about the recognition of the international legal personality of these non-state actors.

Keywords: Governance. Globalization. Non-state actors. Legal personality. International law. 


\section{INTRODUÇÃO}

No cenário mundial, é cada vez mais crescente e influente a presença da governança (com conceito trazido pela Comissão sobre Governança Global, da ONU, de 1992), tendo em vista a implementação de novos processos para a busca de soluções para os problemas comuns. Processos estes que devem envolver tanto os indivíduos, quanto as instituições públicas e privadas.

Neste sentido, a governança fortalece a participação ampliada de outros atores, e não somente dos Estados, ou seja, de atores que não pertencem as estruturas clássicas dos Estados. Demonstrando, assim, a importância e a necessidade da gestão dos problemas entre todos os envolvidos, bem como da cooperação na busca pelas soluções que atendam aos interesses das pessoas e das instituições (sejam públicas ou privadas).

Apesar da característica na ampliação da participação e, da inserção e influência destes atores no cenário global, o Direito Internacional tradicional permanece voltado às relações tão somente entre os Estados, únicos sujeitos de Direito Internacional. O que impede, portanto, que os atores não estatais pratiquem determinados atos, como, por exemplo, a regulação de temas a eles diretamente relacionados.

Neste contexto, o presente artigo visa, primeiramente, abordar a governança, indicando seu conceito e importância. Após, pondera sobre a globalização, lembrando como, a partir dela, cresce o interesse para o estabelecimento de formas de governança nas mais diferentes áreas do conhecimento, bem como aponta as três atuais correntes sobre a globalização.

Em seguida, avalia os atores não estatais nos processos de governança, indicando os principais atores da atualidade, quais sejam: Organizações Intergovernamentais Internacionais, os Movimentos de Libertação Nacional e Oposições Armadas, as Organizações Não Governamentais e as Companhias Multinacionais ou Transnacionais.

Por fim, aborda a controvérsia da personalidade jurídica internacional dos atores não estatais, explicando sobre os "indícios de personalidade" e as atuais teorias sobre o tema, quais sejam: positivista, pluralismo jurídico e funcionalista.

Dessa forma, o presente artigo pretende ressaltar que os atuais mecanismos de governança necessitam da inclusão de todos os atores (estatais 
e não estatais) para a administração e, posterior, solução efetiva do problema, mesmo que a doutrina clássica do Direito Internacional não lhes forneça a condição de "sujeitos de Direito Internacional".

\section{GOVERNANÇA: UMA NOÇÃO INTRODUTÓRIA DA NOVA SISTEMÁTICA GLOBAL}

O atual conceito de "Governança Global” surgiu através da Comissão sobre Governança Global, criado pela Organização das Nações Unidas (ONU), em 1992, como sendo:

[...] a totalidade das diversas maneiras pelas quais os indivíduos e instituições, públicas e privadas, administram seus problemas comuns. É um processo contínuo pela qual é possível acomodar interesses conflitantes e realizar ações cooperativas. Governança diz respeito não só a instituições e regimes formais autorizados a impor obediência, mas a acordos informais que atendam aos interesses das pessoas e instituições (COMISSÃO SOBRE GOVERNANÇA GLOBAL, 1996, p. 2).

Entretanto, desde o início do século XXI, a governança tornou-se uma expressão comum nas áreas das Ciências Humanas, Sociais Aplicadas e afins, como sendo imprescindível para os processos de desenvolvimento tanto econômico quanto social, além de solução para problemas entre Estados e atores não estatais, tendo em vista que é

[...] cada vez maior a preocupação em estabelecer formas e mecanismos de gestão compartilhada do poder, de maneira transparente, onde Estados, Organizações Internacionais, empresas multinacionais e organizações da sociedade civil possam ter papel relevante (GONÇALVES, 2014, p. 83).

A expressão "governança" assume caráter específico no final dos anos 80 (criada com as práticas do Banco Mundial e do Fundo Monetário Internacional, que, em seu conjunto, tinham a intenção de formular princípios e nortear os trabalhos com os países-membros) para designar a capacidade exigida de organizações e governos para a gestão adequada do desenvolvimento sustentável, "adotando políticas sociais e ambientais mais 
rigorosas, e garantindo um papel mais ativo para cidadãos e agentes locais" (GONÇALVES, 2014, p. 84).

Neste sentido, o aumento da interdependência dos povos (fenômeno derivado da globalização) deu origem a diversos problemas que não permaneceram aprisionados as fronteiras dos Estados.

Esta interdependência entre os mais variados atores no cenário internacional torna-se fonte de conflitos, quando

[...] a busca de objetivos por parte de indivíduos pertencentes a um grupo interfere ou impede que outros atinjam as próprias finalidades, mas pode, entretanto, tornar-se a base da cooperação quando surgem oportunidades para aumentar o bem-estar coletivo se forem tomadas medidas de coordenação das ações dos diferentes membros do grupo. Constatada a interdependência entre atores, coordenação e cooperação são elementos-chave para o estabelecimento da governança (GONÇALVES, 2011, p. 47).

Para a solução integrada e comum de tais problemas, torna-se necessária a criação de novas fórmulas.

O aumento da interdependência dos povos torna necessária a criação de novas instituições, que atendam às demandas resultantes da globalização econômica e dos demais fenômenos. A resposta tem sido a criação de regimes internacionais, em um sistema que pode ser denominado 'governança global' (MATIAS, 2005, p. 445).

Percebe-se, portanto, que é necessário para a prática da "boa governança" o reconhecimento de que problemas comuns exigem ações conjuntas com os Estados e a chamada "participação ampliada", compreendida, atualmente, como se tratando das Organizações Internacionais, empresas transnacionais e sociedade civil organizada, ou seja, atores não estatais, definidos como todos os agentes que não pertencem a estrutura estatal, mas que atuam num determinado plano (seja nacional ou internacional), produzindo seus efeitos e, consequentemente, gerando influência.

Assim, não é um processo que exclui a participação dos Estados, mas sim um processo que implica na participação dos mais variados agentes. Tratase da busca de soluções para os problemas envolvendo novos atores. 
Em suma, "governança é um fenômeno mais amplo do que governo; abrange as instituições governamentais, mas implica também em mecanismos informais, de caráter não-governamental” (ROSENAU, 2000, p. 15-16).

Portanto, um dos grandes avanços da Comissão sobre Governança Global citada foi introduzir neste processo novos mecanismos e atores na busca pela construção de um consenso, que é o resultado final de um processo de discussão e interação entre todos os envolvidos naquela problemática.

Vale salientar que, a palavra consenso, neste caso, não é empregada como a busca por unanimidade, mas compreendida como a procura por soluções viáveis e aceitas pela maioria, após a discussão pelos envolvidos.

Governança diz respeito não só a instituições e regimes formais autorizados a impor obediência, mas também a acordos informais que atendem aos interesses de pessoas e instituições [...]. No plano global, a governança foi vista primeiramente como conjunto de relações intergovernamentais, mas agora deve ser entendida de forma mais ampla, envolvendo organizações não governamentais (ONG), movimentos civis, empresas multinacionais e mercados de capital globais. Com estes interagem os meios de comunicação de massa, que exercem hoje enorme influencia (BIERMANN; PATTBERG, 2012, 281).

Assim, diante destas novas fórmulas de solução de problemas, a governança global se distingue das demais, pois não se limita a atuação estatal, mas permite a existência e influência de uma infinidade de atores, que contam com suas próprias estruturas e processos de decisão.

Tal procedimento é corroborado por uma das conclusões do relatório da Comissão sobre Governança Global: "uma enorme variedade de atores pode estar envolvida em qualquer área da governança” (COMISSÃO SOBRE GOVERNANÇA GLOBAL, 1996, p. 3).

With regard to an action-oriented approach, authors have characterized governance as a multi-actor system which extends beyond traditional actors (such as states and international organizations) and includes non-governamental organizations, in particular, activist groups, networks of scientist, business associations and policy research institutions. While states, at least formally, are still the primary actors within this framework, there is a growing number of non-governmental organizations (NGOs), societal movements and other private actors which are transforming the character of the whole system. [...] Last but 
not least, the individual has become increasingly involved as an actor. (BEYERLIN; MARAUHN, 2011, p. 244-246).

O conceito de governança global implica, portanto, em assegurar a participação de diversos atores sociais na resolução dos problemas comuns.

$\mathrm{O}$ crescente interesse para o estabelecimento de formas de governança nas mais diferentes áreas do conhecimento decorrente do processo de globalização.

\section{GLOBALIZAÇÃO}

Globalização, de forma bastante modesta, consiste na integração do que acontece no mundo. Trata-se de uma integralização com características de instantaneidade e velocidade, além de possuir caráter polissêmico, uma vez que abrange mais de uma área, como, por exemplo: cultural, política, jurídica, econômica, entre outras.

Globalization is not a specific object, instead, it is a process. Or more precisely, globalization is a set of accumulating process, resulting from and generating a dialectical whole of political, economic technological, and cultural changes. I define globalization as a multidimensional phenomenon that embodies a shift in organization of human activity and the deployment of power from a local and national orientation towards global patterns, a rising interconnectedness on a global sphere, and a rising awareness of this interconnectedness. (PIERIK, 2004, p. 454).

Com isso, percebe-se que, a globalização tem claramente encolhido as distâncias e aproximado as pessoas.

Não existe uma definição única e universalmente aceita para a globalização. Como acontece com todos os conceitos nucleares das ciências sociais, seu sentido exato é contestável. A globalização tem sido diversamente concebida como ação à distância (quando os atos dos agentes sociais de um lugar podem ter consequências significativas para "terceiros distantes"); como compressão espaço-temporal (numa referência ao modo como a comunicação eletrônica instantânea vem desgastando as limitações da distância e do tempo na organização e na interação sociais); como interdependência acelerada (entendida como 
a intensificação do entrelaçamento entre economias e sociedades nacionais, de tal modo que os acontecimentos de um país tem um impacto direito em outros); como um mundo em processo de encolhimento (erosão das fronteiras e das barreiras geográficas à atividade socioeconômica); e, entre outros conceitos, como integração global, reordenação das relações de poder inter-regionais, consciência da situação global e intensificação da interligação inter-regional (HELD; McGREW, 2001, p. 11).

A globalização abre espaço para a solução dos problemas com base na governança global, uma vez que esta defende a participação dos atores interessados naquele determinado conflito, em nome de uma coexistência social harmoniosa. Trata-se, portanto, de uma participação ampliada visando à solução dos conflitos, mediante a busca de consenso.

\subsection{As Perspectivas a Respeito da Globalização}

A globalização que domina o cenário mundial deste a década de 80 possui três grandes perspectivas a respeito de sua existência e amplitude: hiperglobalista, cética e transformacionalista.

Alguns autores descrevem a perspectiva hiperglobalista como uma abordagem que vê a globalização como uma nova época na história humana. Esta nova época é caracterizada pelo declínio da relevância e autoridade do Estado-nação, provocada em grande parte através da lógica econômica de um mercado global (HIRST, 1997; JONES, 1995).

Dessa forma, para os hiperglobalistas, com a crescente globalização da economia, as organizações de governança transnacional se tornarão cada vez mais importantes e, como resultado, os governos nacionais perderão influência.

Neste sentido, para o professor da Universidade Harvard, Dani Rodrik, é impossível ter simultaneamente democracia, soberania nacional e globalização econômica (RODRIK, 2011). Para preservar a globalização é preciso abdicar ou dos Estados nacionais ou da democracia. Para reforçar a democracia é preciso escolher entre o Estado nacional e a integração econômica mundial. Se o Estado nacional quiser ser preservado, deve-se abrir mão da globalização ou da democracia.

Por outro lado, para os céticos, a belle époque da globalização ocorreu no final do século XIX. Para esta corrente, o que vivemos, na atualidade, 
seria uma "regionalização", por se tratar de processos mais fragmentados do que globalizados (HIRST; THOMPSON, 1999; THOMPSON, 1998; WEISS, 1998).

Em vez de globalização, os céticos concluem que uma conceituação mais válida das tendências atuais seria captada pelos termos 'internacionalização' - isto é, laços crescentes entre econômicas ou sociedades nacionais essencialmente distintas - e 'regionalização' - o agrupamento de trocas econômicas e sociais transfronteiriças. (HELD; McGREW, 2001, p. 15).

Para os autores céticos, a globalização não passa de um mito utilizado para legitimar o neoliberalismo, ou seja, visa consolidar o capitalismo do Ocidente nas principais regiões do mundo. E, com isso, acaba por marginalizar ainda mais os países subdesenvolvidos, ao invés de agregá-los a economia global.

"O conceito de globalização funciona como um 'mito necessário , através do qual os políticos e governos disciplinam seus cidadãos para que eles satisfaçam os requisitos do mercado global" (HELD; McGREW, 2001, p. 16).

Por fim, a perspectiva transformacionalista não crê que exista uma causa única para o processo de globalização, isto é, não ocorre apenas na lógica econômica. Por outro lado, tal corrente analisa a globalização como um conjunto de processos inter-relacionados em todos os campos básicos hoje existentes, como, por exemplo: político, econômico, social, educacional, tecnológico, jurídico, entre outros.

A globalização não pode ser reduzida simplesmente a processos tão somente no setor econômico, pois abrange outras dimensões da dinâmica social, sendo certo que, cada uma destas dimensões avança em ritmo diferente (GIDDENS, 1990; MANN, 1986).

Por conta disso, o resultado do processo de globalização não é determinado, uma vez que uma nova arquitetura mundial está em desenvolvimento.

É inegável o fato de que a globalização existe e que, por ser resultado de múltiplas dimensões atuando em conjunto (conforme mencionado acima), gera, simultaneamente, tanto cooperação quanto conflito, uma vez que faz desaparecer as limitações de espaço e tempo entre as sociedades, 
aproximando-as e colocando-as em constante interação. Esta situação cria a possibilidade de novas organizações sociais, bem como a reordenação do território, inserindo determinadas comunidades num contexto global.

À medida que as atividades econômicas, sociais e políticas transcendem cada vez mais as regiões e as fronteiras nacionais, isso representa um desafio direto para o princípio territorial da organização social e política moderna. Esse princípio pressupõe uma correspondência direta entre a sociedade, a economia e a organização política num território nacional exclusivo e delimitado por fronteiras. Mas a globalização rompe essa correspondência, na medida em que a atividade social, econômica e política já não pode ser entendida como tendo limite idênticos aos das fronteiras territoriais nacionais. (HELD; McGREW, 2001, p. 22).

Diante deste fenômeno, há necessidade de transformação das relações de poder, momento onde a governança pode ser facilmente identificada, devido a necessidade de cooperação internacional.

O resultado desse movimento, intensificado nas últimas décadas, é a redução do poder dos Estados e o aumento do protagonismo de outros atores, como indivíduos, empresas e sociedade civil organizada. Não se trata do fim da soberania estatal, como apregoado por alguns, mas a emergência de um novo paradigma de soberania, fundado em dois conceitos básicos: a capacidade de representação dos interesses aos governados e a legitimidade conferida a suas ações (GONÇALVES, 2014, p. 88).

Neste contexto, surgem novos atores não-estatais de influência internacional, uma vez que a globalização permite a ampliação de relações e atividades sociais, intensificando os fluxos globais.

\section{OS ATORES NÃO ESTATAIS E A GOVERNANÇA GLOBAL}

Os novos atores não estatais podem ser definidos como os agentes que, não pertencem a estrutura estatal, atuam em determinado plano e produzem efeitos.

"If the process of globalization does have an impact on the development of international Law, the practice and opinions of non-state actors can no longer be excluded from an assessment of the law" (NOORTMANN, 2001, p. 74). 
Assim, na atualidade, diante dos avanços tecnológicos na área da comunicação, transporte, informática, bem como diante das relações internacionais e do fenômeno da globalização e da governança (mencionados anteriormente), surge a chamada sociedade global. Dentro dessa, há a ascensão da "sociedade civil transnacional".

"Na sociedade global, os Estados dividem parte de seu poder com outras entidades transnacionais e supranacionais" (MATIAS, 2005, p. 445). Neste contexto, os Estados soberanos convivem com relações muito mais complexas do que aquelas do início do século XX, pois deixaram de ser considerados como únicos atores de Direito Internacional, e passaram a coexistir com outros da "sociedade civil transnacional".

Por "sociedade civil transnacional", pode-se entender "grupos, indivíduos e instituições que são independentes dos Estados e das fronteiras estatais, mas que estão, ao mesmo tempo, preocupados com os assuntos públicos" (KALDOR apud MATIAS, 2005, p. 446). São os chamados atores não estatais.

É evidente que a governança não se resume a ação ou papel de atores não governamentais: ela envolve os Estados, as organizações internacionais, atores não estatais. Mas estes têm papel relevante no processo de governança, vista como forma e processo de resolver problemas comuns (GONÇALVES, 2011, p. 67).

O grupo de atores não estatais compreendem as Organizações Intergovernamentais Internacionais, os Movimentos de Libertação Nacional e Oposições Armadas, as Organizações Não Governamentais e as Companhias Multinacionais ou Transnacionais (NOORTMANN, 2001, p. 60).

A governança, trazendo ao cenário a participação ativa de setores e atores não estatais, contribui sobremaneira para ampliar as contribuições e opiniões capazes de influir nos resultados, seja no campo das políticas públicas, seja na regulação internacional, seja no campo estrito da produção e revisão das normas (GONÇALVES, 2014, p. 99).

No que se refere aos movimentos de libertação nacional e de oposição armada, ganham relevância jurídica internacional a partir do momento em que são reconhecidos. Isto é, para que sejam detentores de direitos ou, ainda, para que se sujeitem as obrigações pactuadas, o grupo deve ser 
reconhecido na ordem jurídica internacional, nos termos do Direito Internacional.

Entretanto, os critérios para reconhecimento devem ser objetivos, bem como a personalidade será transitória e restrita à situação de conflito e seus assuntos. Tome-se, como exemplo, a Organização para Libertação da Palestina (OLP), considerada como sujeito parcial de Direito Internacional, pois tem capacidade legal de manter relações diplomáticas e assinar tratados (NOORTMANN, 2001, p. 68).

Quanto as companhias transnacionais, cresce cada vez mais o número de interações celebradas com os Estados, reguladas pelo Direito Internacional, seja público ou privado, sendo certo que a doutrina contemporânea já não pode mais qualificar estas relações jurídicas apenas como manifestações do princípio da liberdade contratual, tendo em vista que o Direito Internacional impõe direitos e obrigações às companhias. As atividades empresariais não são realizadas fora do âmbito do Direito Internacional.

Ademais, as companhias podem fazer reivindicações legais e serem responsabilizadas com base em instrumentos jurídicos internacionais, especialmente no que diz respeito aos Direitos Humanos.

Entretanto, esta questão ainda é bastante controversa quanto ao conteúdo e o alcance destas companhias no Direito Internacional.

On the basis of the above-mentioned trends in international political and legislative processes, it can be asked whether the status of TNCs has fundamentally change. It is more likely that TNCs are at least in a transitional phase between being object and subject of international law. At the other end of the theoretical spectrum it is even possible to find academics who concluded that the transitional phase has been completed and TNCs must be considered one of the "new subjects of international law' (NOORTMANN, 2001, p. 70).

Para as Organizações Intergovernamentais Internacionais, é possível que tenham finalidade e objetivos próprios. Entretanto, dependem da intenção e vontade dos Estados para que sejam reconhecidas em âmbito internacional.

[As Organizações Internacionais] São associações voluntárias criadas por tratados internacionais, de caráter permanente, das quais os Estados fundadores são membros, e dotadas de regulamento e órgãos de direção próprios, com personalidade jurídica de DIP. Sua finalidade é atingir 
objetivos comuns definidos em sua constituição e pela vontade dos Estados-membros (GONÇALVES, 2014, p. 91).

Por fim, pode-se entender por Organizações Não Governamentais (ONGs), "toda organização que se propõe a representar o Povo e a trabalhar em seu interesse, independentemente das estruturas estatais (e frequentemente contra elas)" (MATIAS, 2005, p. 447).

Devido ao seu crescimento exponencial e a extensão de suas atividades nos mais variados campos, as ONGs têm atuação tanto no cenário interno quanto no internacional, inclusive celebrando acordos com os Estados, como ocorre, por exemplo, com o Comitê Internacional da Cruz Vermelha e o Greenpeace (NOORTMANN, 2001, p. 71). Entretanto, para que haja tal relação jurídica com os Estados, há necessidade de vontade política dos envolvidos.

Além disso, as organizações não-governamentais também colaboram para a governança global, influenciado comportamentos por meio da mídia, pressionando as empresas transnacionais, contribuindo em certa medida para definir como determinados assuntos deverão ser tratados no plano mundial (MATIAS, 2005, p. 463).

Percebe-se, portanto que, tais atores fazem parte intrínseca dos processos de governança, tendo em vista a ideia absorvida por esta de que é necessária a participação ampliada, de todos os envolvidos, ou seja, de outros atores, que não os Estados.

De fato, não se pode negar que os Estados têm figurado no centro do sistema jurídico internacional. Entretanto, tal circunstancia não implica dizer que o Direito Internacional se aplica exclusivamente aos Estados.

O impacto das atividades dos atores não estatais mencionados está crescendo a tal ponto que o papel exclusivo dos Estados nas áreas tradicionais do direito internacional, como, por exemplo, legislação e solução de controvérsias, é questionada.

As is true for public international Law in general, states are not only important actors, but have remained the primary actors in international governance. However, changes that the international legal system in general underwent in the second half of the twentieth century also prompted changes in the role of states in the international law. This 
transformation of the international legal system occurred over a period of years with a broad variety of inputs (BEYERLIN; MARAUHN, 2011, p. 245).

Entretanto, vale salientar que, a noção de Direito Internacional exclusivamente preocupada com os direitos e deveres dos Estados domina a jurisprudência internacional por mais de três séculos, tornando controvertida a atuação internacional dos atores não estatais mencionados.

\subsection{A Controvérsia da Personalidade Jurídica Internacional dos Atores não Estatais}

Embora seja bastante comum reconhecer a existência de atores não estatais, a concepção centrada no Estado como único sujeito de Direito Internacional prevalece, sob o ponto de vista de quatro questionamentos específicos:

1. the existence of an international legal personality of non-state actors;

2. the role of non-states actors in the international law-making process;

3. the position of non-state actors in international dispute-settlement procedures; and

4. the institutional arrangements between international governmental organizations and other non-state, especially non-governmental, organizations (NGOs) (NOORTMANN, 2001, p. 60).

Entende-se como sujeito de Direito Internacional a entidade capaz de possuir direitos e obrigações no plano internacional, bem como de manter seus direitos por meio de ações realizadas em tribunais internacionais.

Neste sentido, para que haja personalidade jurídica no plano internacional, faz-se necessário a observância de três requisitos cumulativos, denominados de "indícios da personalidade": capacidade de apresentar reclamações por violações de Direito Internacional; entrar em relação com outros sujeitos de Direito Internacional, concluindo acordos internacionais válidos; e, usufruir de privilégios e imunidades da jurisdição nacional (NOORTMANN, 2001, 64).

Dessa forma, tradicionalmente, somente os Estados podem ser sujeitos de personalidade jurídica internacional, uma vez que perfazem os três critérios citados. 
Por outro lado, os membros da sociedade civil transnacional (quais sejam: Organizações Intergovernamentais Internacionais, os Movimentos de Libertação Nacional e Oposições Armadas, as Organizações Não Governamentais e as Companhias Multinacionais ou Transnacionais) seriam chamados apenas de atores. Pois, por não possuírem personalidade jurídica internacional, não podem ingressar nos processos de criação de normas internacionais ou participar das decisões sobre assuntos internacionais, mesmo que sejam capazes de influenciar (em diferentes graus) os resultados dos processos sociais no âmbito internacional.

A realidade internacional vem demonstrando que, embora os Estados sejam os únicos sujeitos incontroversos de Direito Internacional, eles não são mais os únicos atores no plano global, uma vez que governança lida com todos estes "novos atores".

Diante dessa realidade, uma teoria positivista e tradicional vê o Direito Internacional como o sistema legal que rege as relações entre os Estados. Estes seriam os únicos constituintes criadores e destinatários do Direito Internacional, ignorando a atuação de qualquer outro ator.

A abordagem positivista estuda o Direito Internacional no que diz respeito e através do comportamento dos Estados (NOORTMANN, 2001, p. 70).

Por outro lado, a corrente do pluralismo jurídico admite a existência e influência de diversos atores no âmbito internacional. Entretanto, o Estado ainda seria o fator relevante no processo de elaboração do Direito Internacional, enquanto que os demais atores teriam papel fundamental na operacionalização de projetos.

In a pluralistic legal system, states are only one relevant factor in the making-law process. IGOs and NGOs participate in the international law-making process in two ways. First, they are involved in operationalising projects which require implementation and interpretation of the relevant rules, and secondly they are involved in settling disputes between the local and the international level (NOORTMANN, 2001, p. 61).

Por fim, a abordagem funcionalista prevê que a atuação desses atores não estatais deve ocorrer em todos os processos de Direito Internacional, porque eles fazem parte do mesmo sistema, bem como são necessários para 
fazer este sistema internacional funcionar com eficiência e justiça (NOORTMANN, 2001, p. 62).

O certo é que, ainda que os Estados sejam encarados como o principal ator de direitos e obrigações no âmbito internacional, os atores não estatais não podem ser excluídos, uma vez que são parte essencial dos processos de governança.

\section{CONSIDERAÇÕES FINAIS}

Em termos bastante modestos, a governança nada mais é do que a gestão e/ou cooperação em nível internacional para a solução de um problema comum.

Nas últimas décadas, os processos de governança foram intensificados pelo avanço da globalização e pela complexividade dos temas envolvidos atualmente nas mais diferentes áreas (como, por exemplo, político, cultural, ambiental, econômico, entre outros), que demandam a ação conjunta de todos os atores interessados.

Não se pode pensar qualquer mecanismo de governança sem a inclusão de todos os atores envolvidos para a solução efetiva do problema comum, tendo em vista que a "governança é um amplo, dinâmico, e complexo processo interativo de tomada de decisão que está constantemente evoluindo e se ajustando a novas circunstâncias" (COMISSÃO SOBRE GOVERNANÇA GLOBAL, 1996, p. 2).

É evidente que, a governança não pode negar a existência e relevância dos Estados, necessitando a participação dos mesmos neste processo, mas, por outro lado, deve contemplar também os demais atores, não estatais (que são, na atualidade, principalmente: Organizações Intergovernamentais Internacionais, os Movimentos de Libertação Nacional e Oposições Armadas, as Organizações Não Governamentais e as Companhias Multinacionais ou Transnacionais), para a administração e obtenção de resultados positivos.

Entretanto, estes "novos atores" não estatais ainda não receberam a alcunha de "sujeitos de Direito Internacional", uma vez que não possuem os chamados "indícios da personalidade": capacidade de apresentar reclamações por violações de Direito Internacional; entrar em relação com outros sujeitos de Direito Internacional, formalizando acordos válidos; e, usufruir de privilégios e imunidades da jurisdição nacional. Por esta razão, mesmo desempenhando papel importantíssimo perante a governança, são chamados de "atores", pois 
não possuem personalidade internacional para regulamentar situações jurídicas ou decidir assuntos no âmbito internacional.

É inegável, no entanto, mesmo diante da ausência de qualificação e definição de status jurídico, a participação dos atores não estatais na busca do consenso, sendo necessários para a construção dos mecanismos de governança.

Dessa forma, os atores não estatais não podem ser preteridos.

Como a atual globalização tem impacto no desenvolvimento do Direito Internacional, na medida em que confere interdependência aos países e interliga os problemas a serem discutidos, bem como conecta os desafios a serem superados pela cooperação internacional, a prática e a necessidade das opiniões e atuação dos atores não estatais não podem ser excluídos, sob pena do eventual processo em que não estiverem presentes não ser considerado um mecanismo de governança.

\section{REFERÊNCIAS}

BEYERLIN, Ulrich; MARAUHN, Thilo. International environmental governance. In: . International enviromental law. Londres: Hart

Publishng, 2011. p. 244-246.

\section{BIERMAN, F.; PATTBERG, P. Global environmental governance} reconsidered. Cambridge: The MIT Press, 2012.

\section{COMISSÃO SOBRE GOVERNANÇA GLOBAL. Nossa comunidade} global: relatório da comissão sobre governança global. Rio de Janeiro: Editora FGV, 1996.

GIDDENS, A. The Consequences of Modernity. Stanford: Stanford University Press, 1990.

GONÇALVES, Alcindo. Governança global e o direito internacional público. In: JUBILUT, Liliana Lyra (Coord.). Direito internacional atual. Rio de Janeiro: Ellsevier, 2014.

GONÇALVES, Alcindo. Governança global e regimes internacionais. São Paulo: Almedina, 2011. 
HELD, David; McGREW, Anthony. Prós e contras da globalização. Rio de Janeiro: Zahar, 2001.

HIRST, P. The Global Economy: Myths and Realities. In International Affairs. vol. 73. n. 3, pp. 409-425. London: Royal Institute of International Affairs, 1997.

HIRST, P.; THOMPSON, G. Globalization in Question. 2.ed. Cambridge: Polity Press, 1999.

JONES, R.J.B. Globalization and Interdependence in the International Political Economy. London: Frances Pinter, 1995.

MANN, Michael. The sources of social Power. Vol I: From the beginning to 1760; vol. II: the rise of classes and nation-states, 1760-1914. Cambridge: Cambridge University Press, 1986.

MATIAS, Eduardo Felipe P. A humanidade e suas fronteiras: do estado soberano à sociedade global. São Paulo: Paz e Terra, 2005.

NOORTMANN, Math. Non-state actors in International Law. In: ARTS, Bas; NOORTMANN, Math; REINALDA, Bob (Ed.). Non-state actors in international relations. Burlington: Ashgate, 2001.

PIERIK, Roland. Globalization and global governance: a conceptual analysis. In: HEERE, W. P. Heere (Org.). Government to governance: the growing impact of non-state actors on the international and european legal system. Cambridge: Cambridge University Press, 2004.

RODRIK, Dani. The globalization paradox: democracy and the future of the world economy. New York: W. W. Norton, 2011.

ROSENAU, James N. Governança, ordem e transformação na política mundial. In: ROSENAU, James N; CZEMPIEL, Ernst-Otto. Governança sem governo: ordem e transformação na política mundial. Brasília: Ed. UnB; São Paulo: Imprensa Oficial do Estado de São Paulo, 2000. 
THOMPSON, G. Globalization versus Regionalism?. In Journal of North African Studies. vol. 3. n.2. New York: Routledge Taylor \& Francis Group, 1998.

WEISS, L. State Capacity: Governing the Economy in a Global Era. Cambridge: Polity Press, 1998.

Submetido em 30/11/2014 Aprovado em 02/03/2015

Como citar: GARCEZ, Gabriela Soldano; FREITAS, Gilberto Passos de. Governança, globalização e atores não estatais: uma análise sob a perspectiva do Direito Internacional. Scientia Iuris, Londrina, v.19, n.2, p.223-240, dez.2015. DOI: 10.5433/2178-8189.2015v19n2p223. ISSN 21788189 . 